\title{
The Interaction of Lexical Tone and Intonation in Mandarin
}

\author{
Jamal A. Khlifat, MA, MSLS \\ Department of Linguistics, University of Colorado, Boulder \\ jamal.khlifat@Colorado.EDU,j.a.khlifat@eagle.clarion.edu
}

\begin{abstract}
How does intonation affect lexical tone in Mandarin? This study examines the interaction of intonation and lexical tone in Mandarin. The study examines specifically the effect of intonational pitch on Tone 2 and Tone 4 in Mandarin. For the purpose of this experiment, we have examined a set of sentences uttered by three Mandarin speakers. The sentences have been uttered using both Tone 2 and Tone 4. Each of these tones has been used in both questions and statements. The study claims that there are more than two linguistic uses for FO (fundamental frequency): lexical tone showing contrasts between words, and intonation distinguishing, among other functions, between different semantic and/or grammatical interpretations of two phrases. It also claims that there is a kind of simultaneous lexical and intonational pitch requirements on a single word. The study concludes that FO at the end of yes/no questions is higher than FO at the end of statements in Mandarin. It also concludes that there is some effect of tone on each of the intonation contour although the t-test indicates that the difference is not significant
\end{abstract}

Keywords: intonation, lexical tone, FO in Mandarin, pitch, intonation pitch

\section{INTRODUCTION}

In the field of phonology, suprasegmental features, such as pitch and intonation, play an important role in the phonological environment as well as the semantic and grammatical function of an utterance. In fact, pitch can be used to signal lexical contrasts. Tone languages, such as Mandarin, specify pitch as well as the segmental quality of each vowel. Since Mandarin has a complex tonal system, it has more tonal contrasts than some tonal languages. This tonal system often involves pitch movement rather than just single points within a pitch range. On the other hand, intonation is viewed as the pitch modulation over an utterance, but it is not that kind of pitch modulation that distinguishes words (lexical tone). Intonation pitch actually affects the semantic/pragmatic, meaning and/or the grammatical function of an utterance. For the purpose of this experiment, investigation has been done to look at the effect of the interaction of lexical tone with intonation in Mandarin Chinese.

In Chinese, there are more than two linguistic uses for F0: lexical tone which shows contrasts between words, and intonation, which, among other functions, might distinguish between different semantic and/or grammatical interpretations of two phrases, for example, between a statement and a question. This leads us to assume that there might be simultaneous lexical and intonational pitch requirements on a single word. Mandarin uses Tone 2, which is a rising tone. This tone rises with a low-final in statements and rises with a high-final in questions. It also uses Tone 4, which is a falling tone. This tone falls with a low-final in statements and falls with a high-final in questions.

\section{LiteratURE REVIEW}

Mandarin has been the domain of research in the field of linguistics in general and phonology and phonetics in particular. Phonologists and phoneticians strive to study this language variety due to the intriguing tonal system that the language has. The language has four discrete and distinct tones characterizing its phonological peculiarity: Tone 1, which is a high level tone, Tone 2 , which is a high rising tone, Tone 3 , which is low falling rising tone, and Tone 4 , which is a high falling tone. Many phoneticians and phonologists like Peter Ladefoged and Keith Johnson made great contributions in studying the tonal system of this language as well as other languages. (Ladefoged\& Johnson, 2010). These tonal systems have been studied separately without direct reference to how they interact with tune or intonation. The purpose of this study is to touch on the gap in literature to bring to light how lexical tone and intonational pitch interact in Mandarin. In attempt to bridge this gap in literature, we have hypothesized the followings whose credibility will be tested as we develop this experiment: 
- F0 at the end of questions is higher than F0 at the end of statements.

- Final Tone 2 will be higher than initial Tone 2

- Initial Tone 4 will be higher than final Tone 4

- Tone 2 for questions will change greater than Tone 2 in statements

- Tone 4 in questions will change lesser than Tone 4 for statements

- Final tone 2 will have higher pitch than final Tone 4 in both statements and questions

3. Methodology

For the purpose of this experiment, we have examined a set of sentences uttered by three Mandarin speakers. The sentences have been uttered using both Tone 2 and Tone 4 . Each of these tones has been used in both questions and statements. The purpose of this study is to examine what happens in these cases where lexical tone and intonation have conflicting requirements for F0. This will help us test the hypotheses listed above. The spectrograms of these utterances have been viewed using Praat. The pitch of each of these utterances has been tracked, and F0 has been measured early in each utterance-final word and then again late in the word. It has been taken into consideration that every Tone 2 utterance-final word will have F0 min before max, and every Tone 4 utterance-final will have F0 max before min.

Data from Jiahong Yuan (LING 5030, Lab 3, University of Colorado Boulder)

Table1. Statements

\begin{tabular}{|l|l|}
\hline st.2.niu & $\begin{array}{l}\text { Luo2yan4 li3bai4wu3 mai4 ye3 niu2 Luoyan Friday sells wild cows ("Luoyan sells wild cows on } \\
\text { Friday.") }\end{array}$ \\
\hline st.2.yang & $\begin{array}{l}\text { Li3bai4wu3 Luo2yan4 yao4 mai3 yang2 Friday Luoyan will buy sheep ("On Friday, Luoyan will } \\
\text { buy sheep.") }\end{array}$ \\
\hline st.4.lu & $\begin{array}{l}\text { Luo2yan4 li3bai4wu3 mai4 ye3 lu4 Luoyan Friday sells wild deer ("Luoyan sells wild deer on } \\
\text { Friday.") }\end{array}$ \\
\hline st.4.la & $\begin{array}{l}\text { Li3bai4wu3 Luo2yan4 yao4 mai3 la4 Friday Luoyan will buy candles ("On Friday, Luoyan will } \\
\text { buy candles.") }\end{array}$ \\
\hline
\end{tabular}

Data from Jiahong Yuan (LING 5030, Lab 3, University of Colorado Boulder)

Table2. Echo Questions

\begin{tabular}{|l|l|}
\hline q.2.niu & $\begin{array}{l}\text { Luo2yan4 li3bai4wu3 mai4 ye3 niu2 Luoyan Friday sells wild cows (“Luoyan sells wild cows on } \\
\text { Friday?”) }\end{array}$ \\
\hline q.2.yang & $\begin{array}{l}\text { Li3bai4wu3 Luo2yan4 yao4 mai3 yang2 Friday Luoyan will buy sheep (“On Friday, Luoyan will } \\
\text { buy sheep?”) }\end{array}$ \\
\hline q.4.lu & $\begin{array}{l}\text { Luo2yan4 li3bai4wu3 mai4 ye3 lu4 Luoyan Friday sells wild deer (“Luoyan sells wild deer on } \\
\text { Friday?”) }\end{array}$ \\
\hline q.4.la & $\begin{array}{l}\text { Li3bai4wu3 Luo2yan4 yao4 mai3 la4 Friday Luoyan will buy candles (“On Friday, Luoyan will } \\
\text { buy candles?”) }\end{array}$ \\
\hline
\end{tabular}

We had to control the independent variables, which are intonational Tone 2 and Tone 4 and the semantic/grammatical environment in relation to the dependent variable, which is the height of the rise/fall of the pitch (F0). Since the target pitch has occurred in different semantic and grammatical environments (utterances) as tables 1 and 2 shows, the set of sentences are divided into 4 additional tables based on the tone and the semantic and grammatical environment. Each tone final-utterance pitch has been measured in each of the two-semantic/grammatical environments: statements and questions.

Table3.F0 of Tone 2 in question

\begin{tabular}{|l|l|l|}
\hline Time & F0 & Description \\
\hline $\mathbf{1 . 2 0 5}$ & 110.66 & 1. Sound q_2_niu_S3 \\
\hline $\mathbf{1 . 4 3 5}$ & 239.78 & 1. Sound q_2_niu_S3 \\
\hline $\mathbf{1 . 3 4 1}$ & 191.27 & 2. Sound q_2_niu_S4 \\
\hline $\mathbf{1 . 6 3 4}$ & 353.84 & 2. Sound q_2_niu_S4 \\
\hline $\mathbf{1 . 4 1 2}$ & 168.1 & 3. Sound q_2_niu_S5 \\
\hline $\mathbf{1 . 6 4 1}$ & 328.24 & 3. Sound q_2_niu_S5 \\
\hline $\mathbf{1 . 3 6 2}$ & 92.54 & 4. Sound q_2_yang_S3 \\
\hline $\mathbf{1 . 5 8 1}$ & 202.85 & 4. Sound q_2_yang_S3 \\
\hline $\mathbf{1 . 3 4}$ & 178.59 & 5. Sound q_2_yang_S4 \\
\hline $\mathbf{1 . 6 6 5}$ & 344.17 & 5. Sound q_2_yang_S4 \\
\hline $\mathbf{1 . 3 5 1}$ & 153.54 & 6. Sound q_2_yang_S5 \\
\hline $\mathbf{1 . 5 6 3}$ & 296.81 & 6. Sound q_2_yang_S5 \\
\hline
\end{tabular}


The Interaction of Lexical Tone and Intonation in Mandarin

Table4.F0 of Tone 4 in question

\begin{tabular}{|l|l|l|}
\hline Time & F0 & Description \\
\hline $\mathbf{1 . 2 7 3}$ & 165.55 & 7. Sound q_4_la_S3 \\
\hline $\mathbf{1 . 3 7 5}$ & 313.99 & 8. Sound q_4_la_S4 \\
\hline $\mathbf{1 . 5 0 1}$ & 232.57 & 8. Sound q_4_la_S4 \\
\hline $\mathbf{1 . 3 3 3}$ & 359.44 & 9. Sound q_4_la_S5 \\
\hline $\mathbf{1 . 5 0 2}$ & 240.95 & 9. Sound q_4_la_S5 \\
\hline $\mathbf{1 . 3 0 1}$ & 231.97 & 10. Sound q_4_lu_S3 \\
\hline $\mathbf{1 . 4 3 4}$ & 137.37 & 10. Sound q_4_lu_S3 \\
\hline $\mathbf{1 . 5 0 7}$ & 339.78 & 11. Sound q_4_lu_S4 \\
\hline $\mathbf{1 . 6 4 3}$ & 245.76 & 11. Sound q_4_lu_S4 \\
\hline $\mathbf{1 . 3 9 9}$ & 358.3 & 12. Sound q_4_lu_S5 \\
\hline $\mathbf{1 . 5 6 4}$ & 215.99 & 12. Sound q_4_lu_S5 \\
\hline
\end{tabular}

Table5.F0 of Tone 2 in statement

\begin{tabular}{|l|l|l|}
\hline Time & F0 & Description \\
\hline $\mathbf{1 . 3 7 1}$ & 89.58 & 13. Sound st_2_niu_S3 \\
\hline $\mathbf{1 . 6 8 3}$ & 134.45 & 13. Sound st_2_niu_S3 \\
\hline $\mathbf{1 . 3 8 1}$ & 175.57 & 14. Sound st_2_niu_S4 \\
\hline $\mathbf{1 . 7 3 6}$ & 255.28 & 14. Sound st_2_niu_S4 \\
\hline $\mathbf{1 . 4 1 6}$ & 138.18 & 15. Sound st_2_niu_S5 \\
\hline $\mathbf{1 . 6 2 2}$ & 211.41 & 15. Sound st_2_niu_S5 \\
\hline $\mathbf{1 . 2 0 3}$ & 80.21 & 16. Sound st_2_yang_S3 \\
\hline $\mathbf{1 . 4 3 4}$ & 133.72 & 16. Sound st_2_yang_S3 \\
\hline $\mathbf{1 . 3 4 3}$ & 171.73 & 17. Sound st_2_yang_S4 \\
\hline $\mathbf{1 . 6 3 9}$ & 231.37 & 17. Sound st_2_yang_S4 \\
\hline $\mathbf{1 . 4 6 7}$ & 76.98 & 18. Sound st_2_yang_S5 \\
\hline $\mathbf{1 . 6 5 5}$ & 194.98 & 18. Sound st_2_yang_S5 \\
\hline
\end{tabular}

Table6.F0 of Tone 4 in statement

\begin{tabular}{|l|l|l|}
\hline Time & F0 & Description \\
\hline $\mathbf{1 . 1 8 4}$ & 133.66 & 19. Sound st_4_la_S3 \\
\hline $\mathbf{1 . 2 7 3}$ & 90.64 & 19. Sound st_4_la_S3 \\
\hline $\mathbf{1 . 6 0 8}$ & 263.4 & 20. Sound st_4_la_S4 \\
\hline $\mathbf{1 . 7 3 8}$ & 174.01 & 20. Sound st_4_la_S4 \\
\hline $\mathbf{1 . 3 8 1}$ & 235.81 & 21. Sound st_4_la_S5 \\
\hline $\mathbf{1 . 4 8}$ & 165.35 & 21. Sound st_4_la_S5 \\
\hline $\mathbf{1 . 3 8 5}$ & 186.25 & 22. Sound st_4_lu_S3 \\
\hline $\mathbf{1 . 3 4 5}$ & 103.1 & 22. Sound st_4_lu_S3 \\
\hline $\mathbf{1 . 5 8 1}$ & 290.7 & 23. Sound st_4_lu_S4 \\
\hline $\mathbf{1 . 7 2 2}$ & 98.04 & 23. Sound st_4_lu_S4 \\
\hline $\mathbf{1 . 3 8 7}$ & 239.18 & 24. Sound st_4_lu_S5 \\
\hline $\mathbf{1 . 4 9 3}$ & 80.79 & 24. Sound st_4_lu_S5 \\
\hline
\end{tabular}

Taking into consideration that Tone 2 is a rising tone, and Tone 4 is a falling one, and based on the data and measurements collected regarding the two tones as well as the two semantic/grammatical environments, we can make accurate predictions in regard to what happens in these cases where lexical tone and intonation have conflicting requirements for F0.

\section{DisCuSSION}

Upon calculating and taking into consideration the means of each group as well as subgroup in tables 3, 4, 5 and 6 and upon running a t-test to assess the probability if the null hypotheses are correct as well as to assess the hypotheses being tested, we have obtained accurate predictions about the data being tested.

The null hypothesis here is the dummy hypothesis that assumes that there are no differences in the hypotheses under investigation. In our approach, we have performed the t-test using paired data, i.e., every pair consists of F0 in the two contrasting environments that the hypothesis in question addresses. We have adopted the two-tailed test to see if the means could differ in both directions. We have also assumed that variances are equal. 
While the means of F0 of Tone 2 and Tone 4 in questions is $222 \mathrm{~Hz}$ and $258 \mathrm{~Hz}$, respectively, the means of F0 of Tone 2 and Tone 4 in statements is $154 \mathrm{~Hz}$ and $180 \mathrm{~Hz}$, respectively $(\mathrm{P}<.05$ $\mathrm{P}=.0431$ ). This means that the difference is significant. In the same time, while the standard deviation of F0 of Tone 2 and Tone 4 in questions is $87 \mathrm{~Hz}$ and $72 \mathrm{~Hz}$, respectively, the standard deviation of F0 of Tone 2 and Tone 4 in statements is $58 \mathrm{~Hz}$ and $67 \mathrm{~Hz}$ respectively. This reinforces the first hypothesis, which states that "F0 at the end of questions is higher than F0 at the end of statements." According to the t-test result, the difference is significant; it is smaller than Alpha.

While the means of F0 for final Tone 2 in questions and statements is $294 \mathrm{~Hz}$ and $194 \mathrm{~Hz}$, respectively, the means of F0 for initial Tone 2 in questions and statements is $149 \mathrm{~Hz}$ and $122 \mathrm{~Hz}$, respectively $(\mathrm{P}=\mathrm{P}$-value, $\mathrm{P}>.05 \mathrm{P}=0.20)$. As the $\mathrm{t}$-test result shows, we have failed to show that the null hypothesis is incorrect. $\mathrm{P}$ is bigger than Alpha. This means the difference is not significant, and it does not reinforce the second hypothesis, which states that "Final Tone 2 will be higher than initial Tone 2. In the same time, while the means of the standard deviation of F0 for final Tone 2 in questions and statements is $56 \mathrm{~Hz}$ and $46 \mathrm{~Hz}$, respectively, the means of the standard deviation for initial tone 2 in questions and statements is $34 \mathrm{~Hz}$ and $42 \mathrm{~Hz}$, respectively. According to the t-test result, the difference is not significant; it is bigger than Alpha.

While the means of F0 for initial Tone 4 in questions and statements is $317 \mathrm{~Hz}$ and $225 \mathrm{~Hz}$, respectively, the means of F0 for final Tone 4 in questions and statements is $206 \mathrm{~Hz}$ and $119 \mathrm{~Hz}$, respectively $(\mathrm{P}<.05 \mathrm{P}=.0146)$. This means that the difference is significant. This reinforces the third hypothesis, which states that "Initial Tone 4 will be higher than final Tone 4." $(\mathrm{P}<.05)$ is smaller than Alpha. In the same time, while the means of the standard deviation of F0 for initial Tone 4 in questions and statements is $44 \mathrm{~Hz}$ and $51 \mathrm{~Hz}$, respectively, the means of the standard deviation of F0 for final Tone 4 in questions and statements is $41 \mathrm{~Hz}$ and $37 \mathrm{~Hz}$, respectively.

While the means of the difference of F0 between initial and final Tone 2 in questions is $145 \mathrm{~Hz}$, the means of the difference of $\mathrm{F} 0$ between initial and final Tone 2 in statements is $71 \mathrm{~Hz}(\mathrm{P}<.05 \mathrm{P}=$ .00143). As the t-test result shows, this refutes the null hypothesis; $\mathrm{P}$ is smaller than Alpha. This means the difference is significant, and it does reinforce the fourth hypothesis, which states that "Tone 2 for questions will change greater than Tone 2 in statements." In the same time, while the means of the difference in the standard deviation of F0 between initial and final Tone 2 in questions is $20 \mathrm{~Hz}$, the means of the difference in the standard deviation of F0 between initial and final Tone 2 in statements is $24 \mathrm{~Hz}$. According to the t-test result, the difference is significant; it is smaller than Alpha.

While the means of the difference of F0 between initial and final Tone 4 in questions is $110 \mathrm{~Hz}$, the means of the difference of F0 between initial and final Tone 4 in statements is $106 \mathrm{~Hz}$ ( $\mathrm{P}=\mathrm{P}$-value, $\mathrm{P}$ $>.05 \mathrm{P}=0.878$ ). As the t-test result shows, we have failed to show that the null hypothesis is incorrect. $\mathrm{P}$ is bigger than Alpha. This means the difference is not significant, and it does not reinforce the fifth hypothesis, which states that "Tone 4 in questions will change lesser than Tone 4 for statements. In the same time, while the means of the difference in the standard deviation of F0 between initial and final Tone 4 in questions is $22 \mathrm{~Hz}$, the means of the difference in the standard deviation of F0 between initial and final Tone 4 in statements is $52 \mathrm{~Hz}$. According to the t-test result, the difference is not significant; it is bigger than Alpha.

While the means of F0 for final Tone 2 in both questions and statements is $294 \mathrm{~Hz}$ and $194 \mathrm{~Hz}$, respectively, the means of $\mathrm{F} 0$ for final Tone 4 is $206 \mathrm{~Hz}$ and $119 \mathrm{~Hz}$, respectively, ( $\mathrm{P}=\mathrm{P}$-value, $\mathrm{P}$ > $.05 \mathrm{P}=0.0506)$. As the t-test result shows, we have failed to show that the null hypothesis is incorrect. $\mathrm{P}$ is bigger than Alpha. This means the difference is not significant, and it does not reinforce the sixth hypothesis, which states, "Final Tone 2 will have higher pitch than final Tone 4 in both statements and questions." In the same time, while the means of the standard deviation of F0 for final Tone 2 in questions and statements is $56 \mathrm{~Hz}$ and $49 \mathrm{~Hz}$ respectively, the means of the standard deviation of F0 for final Tone 4 in questions and statements is $41 \mathrm{~Hz}$ and $37 \mathrm{~Hz}$, respectively. According to the t-test result, the difference is not significant; it is bigger than Alpha.

\section{RESULTS}

Based on the analysis done and the results collected from the t-test as well as the means and standard deviations of the targeted hypotheses, the following can be concluded: 
Hypothesis 1.Hypothesis 1, which states, "F0 at the end of questions is higher than F0 at the end of statements" has been supported. According to the t-test result, $(\mathrm{P}<.05 \mathrm{P}=.0431)$, the difference is significant.While the means of F0 of Tone 2 and Tone 4 in questions is $222 \mathrm{~Hz}$ and $258 \mathrm{~Hz}$, respectively, the means of F0 of Tone 2 and Tone 4 in statements is $154 \mathrm{~Hz}$ and $180 \mathrm{~Hz}$. This means the pitch of Tone 2 and Tone 4 at the end of questions is higher than the pitch of Tone 2 and Tone 4 at the end of statements, and the difference is significant. The difference is significant because it is smaller than Alpha. Graph 1 shows this relation.

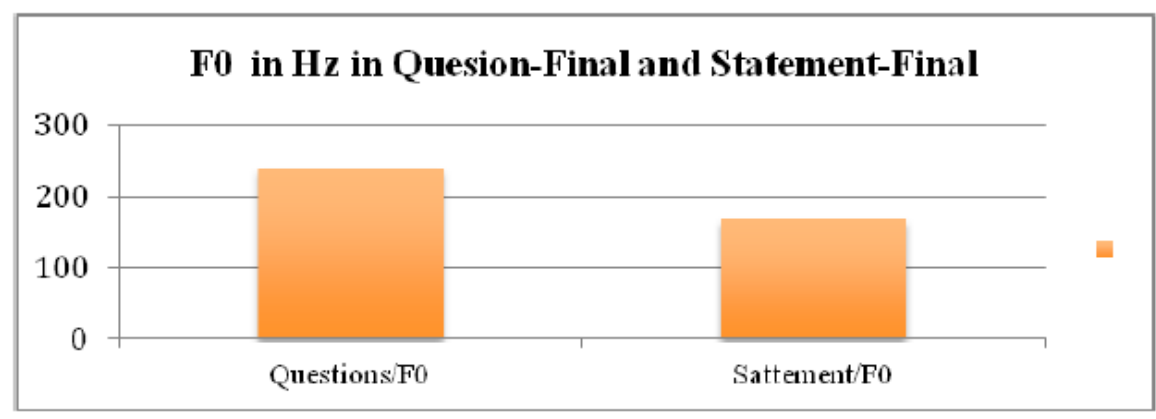

Graph1. FO in $\mathrm{Hz}$ in question-final and statement-final

Hypothesis 2.Hypothesis 2 which states that, "Final Tone 2 will be higher than initial Tone 2" has not been reinforced based on the t-test result obtained, $(\mathrm{P}=\mathrm{P}$-value, $\mathrm{P}>.05 \mathrm{P}=0.20)$. $\mathrm{P}$ is bigger than Alpha. This means the difference is not significant. While the means of F0 for final Tone 2 in questions and statements is 294 and $194 \mathrm{~Hz}$, respectively, the means of F0 for initial Tone 2 in questions and statements is $149 \mathrm{~Hz}$ and $122 \mathrm{~Hz}$, respectively. As the t-test result shows, we have failed to show that the null hypothesis is incorrect. Graph 2 shows this relation.

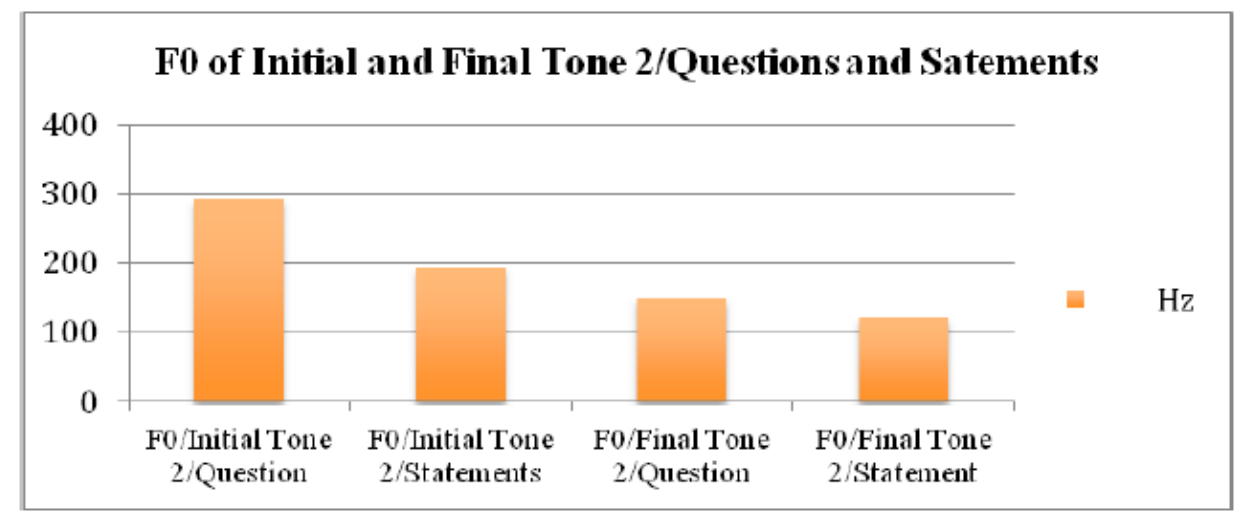

Graph2. FO of initial and final Tone 2/question and statement

Hypothesis 3.Hypothesis 3, which states, "Initial Tone 4 will be higher than final Tone 4" has been supported based on the t-test result obtained, $(\mathrm{P}<.05 \mathrm{P}=.0146)$. This means that the difference is significant since $\mathrm{P}$ is $<.05$. While the means of $\mathrm{F} 0$ for initial Tone 4 in questions and statements is 317 $\mathrm{Hz}$ and $225 \mathrm{~Hz}$, respectively, the means of F0 for final Tone 4 in questions and statements is $206 \mathrm{~Hz}$ and $119 \mathrm{~Hz}$, respectively. Graph 3 shows this relation.

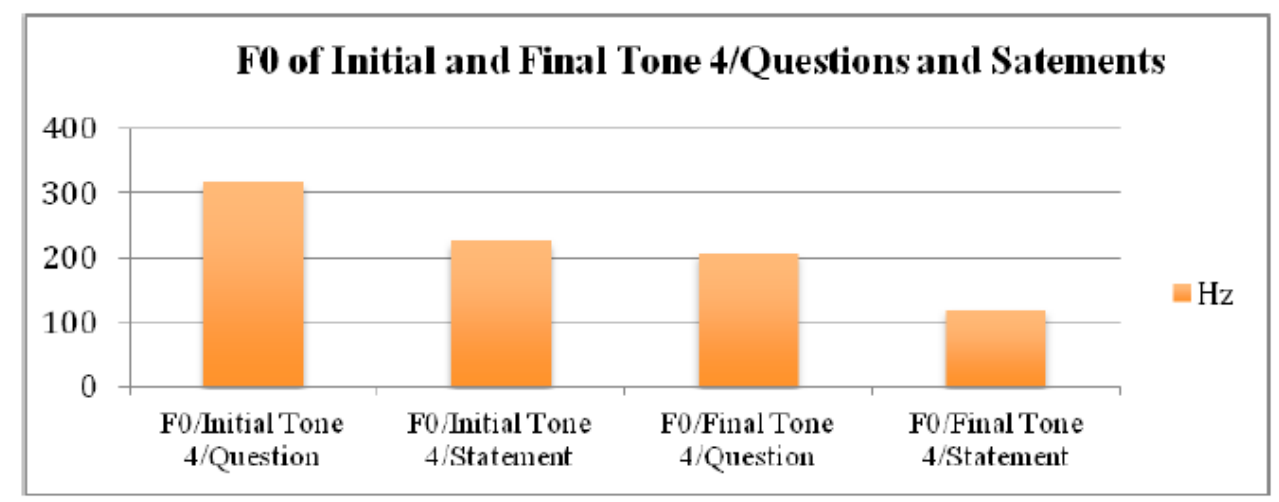

Graph3. F0 of initial and final Tone 4/question and statement 
Hypothesis 4.Hypothesis 4, which states, "Tone 2 for questions will change greater than Tone 2 in statements" has been supported based on the t-test result obtained, $(\mathrm{P}<.05 \mathrm{P}=.00143)$. As the t-test result shows, we have succeeded in supporting my hypothesis and refuting the null hypothesis. $\mathrm{P}$ is smaller than Alpha. This means the difference is significant. While the means of the difference of F0 between initial and final Tone 2 in questions is $145 \mathrm{~Hz}$, the means of the difference of F0 between initial and final Tone 2 in statements is $71 \mathrm{~Hz}$. Graph 4 shows this relation.

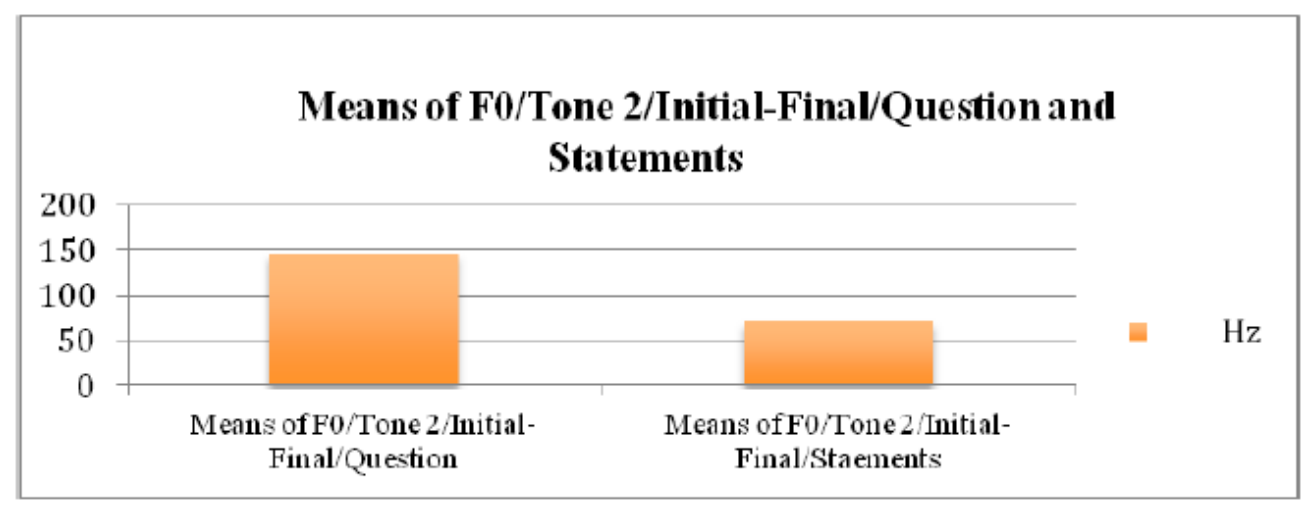

Graph4. Means of FO of Tone 2 in both initial-final question and initial-final statement

Hypothesis 5.Hypothesis 5, which states, "Tone 4 in questions will change lesser than Tone 4 for statements" has not been supported based on the t-test result obtained, $(\mathrm{P}=\mathrm{P}$-value, $\mathrm{P}>.05 \mathrm{P}=$ 0.878). This means that the difference is not significant since $(\mathrm{P}>.05)$ i.e., bigger than Alpha. While the means of the difference of F0 between initial and final Tone 4 in questions is $110 \mathrm{~Hz}$, the means of the difference of F0 between initial and final Tone 4 in statements is $106 \mathrm{~Hz}$. Graph 5 shows this relation.

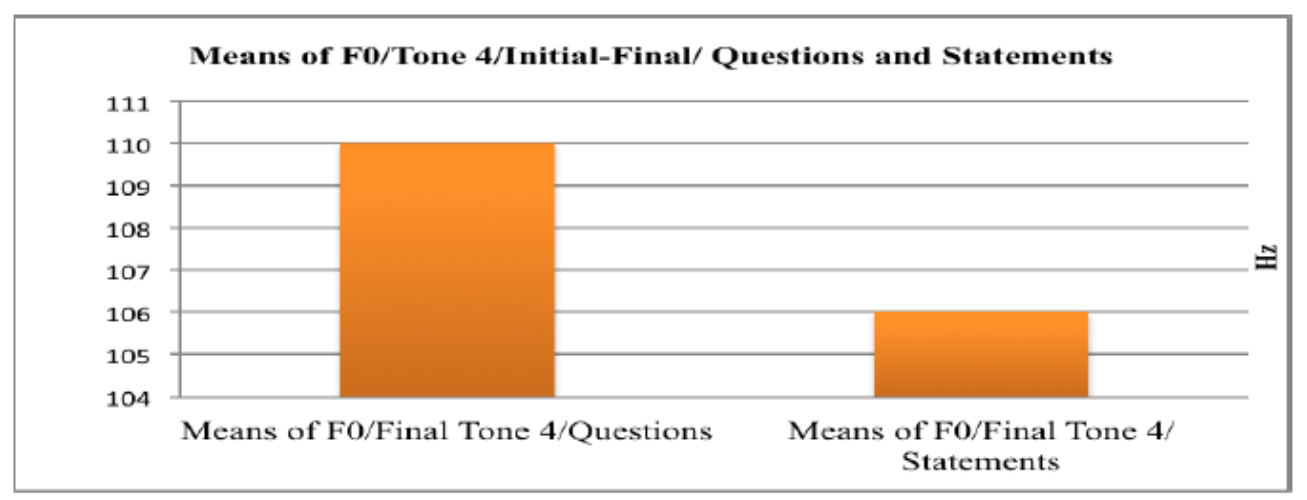

Graph5. Means of FO of Tone 4 in both initial-final question and initial-final statement

Hypothesis 6.Hypothesis 6, which states, "Final Tone 2 will have higher pitch than final Tone 4 in both statements and questions" has not been supported based on the t-test results obtained, $(\mathrm{P}=\mathrm{P}$ value, $\mathrm{P}>.05 \mathrm{P}=0.0506$ ). As the t-test result shows, we have failed to show that the null hypothesis is incorrect. $\mathrm{P}$ is bigger than Alpha. This means the difference is not significant. While the means of F0 for final Tone 2 in both questions and statements is 294 and $194 \mathrm{~Hz}$, respectively, the means of F0 for final Tone 4 in both questions and statements is $206 \mathrm{~Hz}$ and $119 \mathrm{~Hz}$, respectively. Graph 6 shows this relation.

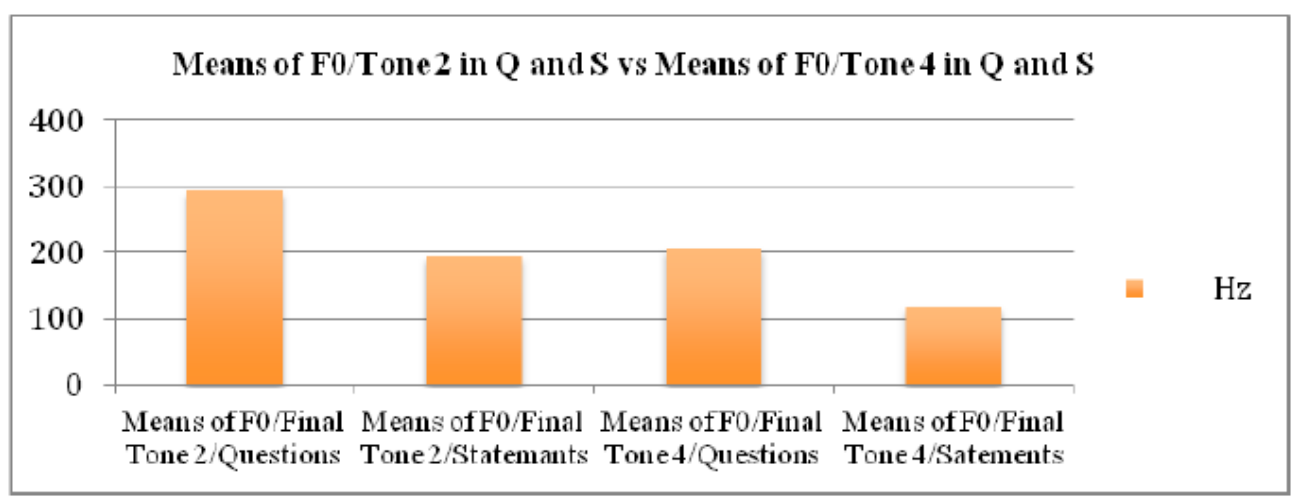

Graph6. Means of FO of Tone 2 in question and statement vs. means of FO of Tone 4 in question and statement 


\section{Conclusion}

Based on the results and the statistics obtained from the t-test as well as from the means and the standard deviations of the data investigated in the hypotheses above, it is obvious that $\mathrm{F} 0$ at the end of yes/no questions is higher than F0 at the end of statements in Mandarin, $(\mathrm{P}<.05 \mathrm{P}=.0431)$. The difference is really significant. It is also obvious that while lexical Tone 2 is not really preserved (correctly realized) sentence finally, $(\mathrm{P}=\mathrm{P}$-value, $\mathrm{P}>.05 \mathrm{P}=0.20$; the difference is not significant), lexical Tone 4 is really preserved (correctly realized) sentence finally, $(\mathrm{P}<.05 \mathrm{P}=.0146$; the difference is significant). It is also obvious that intonation affects the change in Tone 2 (while the transition from a question to a statement) in a greater degree since the change in questions is greater than the change in statements, $(\mathrm{P}<.05 \mathrm{P}=.00143$; the difference is significant $)$. In the same time, intonation does not greatly affect Tone 4 in transitions from a statement to a question, $(\mathrm{P}=\mathrm{P}$-value, $\mathrm{P}$ $>.05 \mathrm{P}=0.878$; the difference is not significant). It is also obvious that there is some effect of tone on each of the intonation contour although the t-test indicates that the difference is not significant, $(\mathrm{P}=\mathrm{P}-$ value, $\mathrm{P}>.05 \mathrm{P}=0.0506$ ). This is because $\mathrm{P}$ almost has the same value as Alpha.

\section{REFERENCES}

Johnson, K. (2012). Acoustic and auditory phonetics ( $3^{\text {rd }}$ ed.). Chichester: Wiley-Blackwell.

Ladefoged, P., \& Johnson, K. (2010). A course in phonetics (6 ${ }^{\text {th }}$ ed.). Boston, MA: Cengage Learning, Inc.

Scarborough, Rebecca. (2014). Linguistics phonetics: Lab3: Lexical tone and intonation in Mandarin Chinse. Boulder, CO: University of Colorado Boulder.

\section{AUTHOR's BIOGRAPHY}

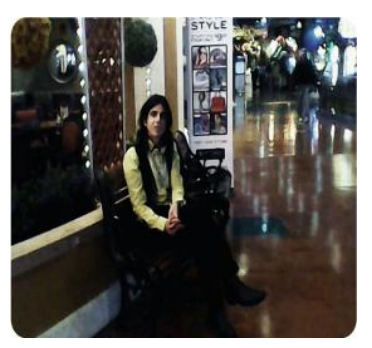

Jamal A. Khlifat, was born with a malleus in my ear enabling me to distinguish the different sounds exist in the disputed number of the world's languages. I am into anatomizing those abstract units called phonemes to examine the phonetic variations that can be observed. There is nothing as intriguing as tracing the different forms a spoken message exists in its progress from the speaker's mind to the listener's. How this peculiar linguistic signal is converted into an acoustic one, which is, in turn, converted into an electro-chemical signal in the brain, to be later on decoded into segments; words; and, ultimately, meaning, reveals the supernatural power that has created this physiological linguistic apparatus.

Research Interest: forensic linguistics, phonetics, phonology, documentation of the world's endangered languages, pharyngealization and pharyngeal harmony in Levantine Arabic, gemination in Levantine Arabic, nasalization and nasal geminates in Levantine Arabic, syntax, lexical semantics, prosody, and rhetoric and Toulmin argumentation 